\title{
Combining HLA-DRB1-DQB1 and Mycobacterium Avium Subspecies Paratubercolosis (MAP) antibodies in Sardinian multiple sclerosis patients: associated or independent risk factors?
}

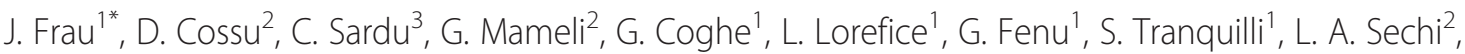 \\ M. G. Marrosu ${ }^{4}$ and E. Cocco ${ }^{1}$
}

\begin{abstract}
Background: Amongst Sardinians the human leukocyte antigen (HLA) DRB1-DQB1 haplotypes *15:02-*06:01, *16: 01-*05:02, ${ }^{*}$ 14:01-4-*05:03 are protective for multiple sclerosis (MS), while ${ }^{*}$ 13:03-*03:01, ${ }^{*} 04: 05-{ }^{*} 03: 01,{ }^{*} 03: 01-* 02: 01$, *15:01-*06:02 and Mycobacterium avium subspecies paratubercolosis (MAP) are predisposing factors. We studied the correlation between MAP and HLA.

Methods: Five hundred thirty-one patients were searched for anti-MAP2694 antibodies, DRB1-DQB1 genotyping was performed. The haplotypes were classified as predisposing, neutral or protective.

Results: Anti-MAP2694 were found in $23 \%$ of subjects carrying one protective HLA versus $32 \%$ without ( $p=0.04$ ). Conclusions: We showed a lower frequency of Abs in patients with protective HLA. These haplotypes could have a protective role for both MS and MAP.
\end{abstract}

Keywords: Mycobacterium avium subspecies paratuberculosis, Multiple sclerosis, HLA, Sardinia

Abbreviations: Abs, Antibodies; EBV, Epstein-barr virus; HC, Healthy controls; HLA, Human leukocyte antigen; MS, Multiple sclerosis; MAP, Mycobacterium avium subspecies paratubercolosis

\section{Background}

Multiple Sclerosis (MS) is a multifactorial disease shaped by both genetic and environmental factors. In Sardinia, an Italian island with a very high prevalence of the disease, the genetics of MS have some peculiarities. In particular, there is a negative association with the DRB1DQB1 human leukocyte antigen (HLA) haplotypes "15:02-"06:01, "16:01-"05:02 and "14:01-4-"05:03 and a positive association with "13:03-"03:01, "04:05-"03:01, "03:01-"02:01 and "15:01-"06:02 [1]. The last of these is the main genetic risk factor for MS in Northern European

\footnotetext{
* Correspondence: jessicafrau@hotmail.it

${ }^{1}$ Multiple Sclerosis Centre, Department of Public Health, Clinical and

Molecular Medicine, University of Cagliari, Cagliari, Italy

Full list of author information is available at the end of the article
}

populations, [2] it gives Sardinians a strong predisposition to MS, but is very rare in this population [3]. Concerning environmental factors, an association between MS and Mycobacterium avium subspecies paratubercolosis (MAP) was identified on the island [4]. MAP is an endocellular pathogen, it is present in $39.2 \%$ of patients and in $6 \%$ of healthy controls $(\mathrm{HC})$ in the Sardinian population. It could be a trigger for the disease by means of a molecular mimicry mechanism and the spreading of epitopes [5].

In recent years, many studies have focused on the possibility of a relationship between genetic and infectious factors in conferring risk of MS, in particular between predisposing HLA and Epstein-Barr virus (EBV) [6-8]. The studies yielded conflicting results (negative interaction in 
Table 1 Clinical and demographic data of patients included in the study

\begin{tabular}{|c|c|c|c|c|c|c|c|c|c|c|c|c|c|}
\hline \multirow[t]{2}{*}{ 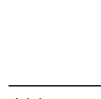 } & \multirow[t]{2}{*}{ Mean age } & \multirow[t]{2}{*}{ Median EDSS } & \multicolumn{3}{|c|}{ Course } & \multicolumn{7}{|c|}{ Therapy } & \multirow[t]{2}{*}{ Steroids } \\
\hline & & & $\mathrm{RR}$ & $\mathrm{SP}$ & $\mathrm{PP}$ & NONE & IFN & GA & NAT & FING & MIX & $A Z A$ & \\
\hline ALL & $43 y$ & 2.5 & $82 \%$ & $13 \%$ & $5 \%$ & $31 \%$ & $25 \%$ & $18 \%$ & $10 \%$ & $12 \%$ & $1 \%$ & $3 \%$ & $6 \%$ \\
\hline $\mathrm{MAP}+$ & $41 \mathrm{y}$ & 2 & $81 \%$ & $15 \%$ & $4 \%$ & $29 \%$ & $27 \%$ & $17 \%$ & $10 \%$ & $13 \%$ & $0 \%$ & $4 \%$ & $5 \%$ \\
\hline MAP- & $44 y$ & 2.5 & $84 \%$ & $10 \%$ & $6 \%$ & $32 \%$ & $26 \%$ & $16 \%$ & $11 \%$ & $13 \%$ & $1 \%$ & $1 \%$ & $6 \%$ \\
\hline
\end{tabular}

$R R$ relapsing remitting, $S P$ secondary progressive, $P P$ primary progressive, IFN beta interferon, GA glatiramer acetate, NAT natalizumab, FING fingolimod, MIX mitoxantrone, $A Z A$ azathioprine

the first study, and positive in two others). Other studies aimed to investigate the influence of genotype on levels of humoral response to EBV. Waubant et al. showed higher levels of EBNA-1 antibodies (Abs) in HLA-DRB1 positive patients [9]. Rubicz et al. used a genome-wide approach to analyze the SNPs associated with EBV-related diseases, finding an association between EBNA-1 Abs levels and HLA [8].

There are no studies focused on the relationship between HLA and MAP.

We aimed to search for possible relationships between the presence of anti-MAP Abs and predisposing/protective HLA in MS patients.

\section{Methods}

A group of MS patients, diagnosed according to McDonald criteria 2010 [10], was enrolled in the study after giving informed written consent. They were recruited randomly from the MS center of the University of Cagliari, between patients performing routine visits. The only inclusion criterion was to have a diagnosis of MS (McDonald 2010) and there were not exclusion criteria. In fact, in a previous study, we did not find association between presence of anti-MAP antibodies and clinical variables [5]. The University of Cagliari ethical committee approved the study and the informed consent. The clinical and demographic variables are reported in Table 1. For each subject a blood sample was collected and analyzed for the presence of anti-MAP2694 Abs by indirect ELISA, as previously described [4]. Moreover, DNA was extracted to perform DRB1-DQB1 HLA genotyping and the haplotypes were classified as predisposing (*13:03-*03:01, *04:05-"03:01, "03:01-*02:01, "15:01-*06:02) or protective ("15:02-"06:01, *16:01-"05:02, *14:01-4-"05:03), according to the previous study [1]. Other haplotypes were considered neutral.

\section{Statistical analysis}

The Pearson's chi squared test was used for the haplotypes and genotypes analysis. For the former, protective haplotypes versus neutral and predisposing were considered. The analysis was repeated considering neutral and predisposing haplotypes together. In the genotypes analysis, the presence of at least one protective haplotype versus its absence was evaluated.

\section{Results}

The study enrolled 531 patients, 372 females and 159 males $(\mathrm{F}: \mathrm{M}=2.3: 1)$. MAP negative subjects carried a total of 109 (15\%) protective, 317 (44 \%) neutral and 296 (41 \%) predisposing HLA haplotypes, while MAP positive patients carried a total of $33(11 \%)$ protective, 140 (46\%) neutral and 133 (43\%) predisposing HLA haplotypes $(p=0.19)$ Table 2 . When considering protective HLA versus combined neutral and predisposing ones, MAP negative patients carried 613 (85\%) neutral or predisposing and 109 (15\%) protective HLA haplotypes, while MAP positive subjects carried 273 (89\%) neutral or predisposing and $33(11 \%)$ protective haplotypes $(p=0.07)$ Table 3.

The analysis of the genotypes showed that the protective alleles were carried by 134 patients. The number of patients carrying at least one protective haplotype was 31 $(20 \%)$ in MAP positive and 103 (29\%) in MAP negative patients $(p=0.05)$ Table 4.

\section{Discussion}

Sardinian MS patients have some genetic and environmental peculiarities. They carried predisposing and protective haplotypes different from those carried by other MS populations [1]. Moreover, nowadays, it is only in Sardinia that the disease is associated with MAP infection $[4,5]$. An interesting field of research is the possible interaction between the HLA haplotypes and the presence of anti-MAP Abs in conferring MS risk. Recently, a molecular modeling approach was used to find the differences between the Sardinian predisposing $\left({ }^{*} 03: 01\right.$ and $\left.{ }^{*} 15: 01\right)$ and protective (*16:01 and $\left.{ }^{*} 15: 02\right)$ HLA in

Table 2 Analysis of haplotypes: protective versus neutral versus predisposing. Pearson's chi squared $(p=0.19)$

\begin{tabular}{lllll}
\hline & & $\begin{array}{l}\text { Protective } \\
\text { haplotypes }\end{array}$ & $\begin{array}{l}\text { Neutral } \\
\text { haplotypes }\end{array}$ & $\begin{array}{l}\text { Predisposing } \\
\text { haplotypes }\end{array}$ \\
\hline Anti-MAP2694 Abs & Negative & $109(15 \%)$ & $317(44 \%)$ & $296(41 \%)$ \\
& Positive & $33(11 \%)$ & $140(46 \%)$ & $133(43 \%)$ \\
\hline
\end{tabular}


Table 3 Analysis of haplotypes: protective versus combined neutral and predisposing. Pearson's chi squared ( $p=0.07$ )

\begin{tabular}{llll}
\hline & & $\begin{array}{l}\text { Neutral or predisposing } \\
\text { haplotypes }\end{array}$ & $\begin{array}{l}\text { Protective } \\
\text { haplotypes }\end{array}$ \\
\hline Anti-MAP2694 Abs & Negative & $613(85 \%)$ & $109(15 \%)$ \\
& Positive & $273(89 \%)$ & $33(11 \%)$ \\
\hline
\end{tabular}

recognizing MAP peptide. The former were found able to bind the MAP peptide better than the protective ones, suggesting a higher presentation efficiency, a higher probability of T-cell activation and autoimmune reaction [11].

In our study the analysis of the haplotypes showed no significant difference in frequency of predisposing, protective and neutral haplotypes among $\mathrm{MAP}+$ and MAP- patients, suggesting that MAP infection and predisposing haplotypes are independent risk factors. This is in line with the study of De Jager et al., that analyzed the association between EBV infection, evaluating the levels of anti-EBNA-1 Abs and the presence of DRB1*1501 [6]. They concluded that both factors independently contributed to an increased MS risk. In their study no predisposing HLA were considered [6].

On the other hand, Rubicz et al. analyzed 30 genomewide significant MS SNPs and found an association between EBNA-1 quantitative trait and SNP rs9271366, and between EBNA-1 serostatus trait (positive or negative) and SNPs rs3129860 and rs3135388. All these SNPs are located within HLA-DR and HLA-DQ genes, suggesting that this region is important both for EBV-related and autoimmune responses [8].

Sunqvist et al. found an interaction between EBNA: $385-420$ IgG and the presence of DRB1*15. They concluded that the mechanism through which HLA influences MS risk could involve the immune control of EBV infection. They also evaluated the protective haplotype A*02, demonstrating the interaction between its absence and the presence of the same Abs [7].

This last point is in line with the findings in our study. In fact, the analysis of haplotypes identified a trend towards a lower frequency of Abs in patients with protective haplotypes. The analysis of genotypes confirmed this finding, showing a significantly lower presence of anti-MAP Abs in

Table 4 Analysis of genotypes: Absence versus presence of at least one protective haplotype. Pearson's chi squared $(p=0.05)$

\begin{tabular}{llll}
\hline & $\begin{array}{l}\text { Absence of protective } \\
\text { haplotypes }\end{array}$ & $\begin{array}{l}\text { At least one protective } \\
\text { haplotypes }\end{array}$ \\
\hline Anti-MAP2694 Negative & $258(71 \%)$ & $103(29 \%)$ \\
Abs & Positive & $122(80 \%)$ & $31(20 \%)$ \\
\hline
\end{tabular}

patients carrying at least one protective HLA versus patients without.

We did not find an association between the presence of Abs and predisposing HLA.

\section{Conclusions}

In conclusion, on the basis of our data, we could hypothesize that both genetic and MAP have an independent role in conferring MS risk.

Moreover, considering the demonstration of lower frequency of anti-MAP Abs in patients with protective HLA, it is possible that these haplotypes play a role in protecting not only against MS but against MAP infection as well.

\section{Acknowledgements}

None.

\section{Funding}

This investigation was supported by FISM - Fondazione Italiana Sclerosi Multipla - Cod. 2012/R/3, Fondazione di Sardegna 2012 "Fattori ambientali e Sclerosi multipla in Sardegna: Ruolo del micobacterium Avium Subspecies Paratuberculosis sul fenotipo di malattia".

\section{Availability of data and materials}

All necessary data are included in the manuscript. The authors have no supplementary data to share. We can not publish the raw data because in the informed consent we declared that the data will be shared only with the staff involved in the study. The patients authorized us to divulge only the results by scientific publications or conferences. Moreover, we are conducting other studies using the same data.

\section{Authors' contribution}

JF: study design, acquisition of data, interpretation of data, drafting the manuscript. DC: laboratory analysis and analysis of data. CS: statistical analysis. GM: laboratory analysis and analysis of data. GC: acquisition of data, interpretation of data, drafting the manuscript. LL: acquisition of data, interpretation of data, drafting the manuscript. GF: acquisition of data, interpretation of data, drafting the manuscript. ST: laboratory analysis. LAS: laboratory analysis and analysis of data, revision of the manuscript. MGM: study design, interpretation of data, revision of the manuscript. EC: study design, acquisition of data, interpretation of data, revision of the manuscript. All authors read and approved the last version of the manuscript.

\section{Competing interests}

On behalf of all authors, the corresponding author states that there is no conflict of interest about this work.

\section{Ethics approval and consent to participate}

The University of Cagliari ethical committee approved the study and the informed consent.

\section{Consent for publication}

In the informed consent approved by the University of Cagliari ethical committee, the patients authorized us to share the results of the studies by scientific publications or conferences.

\section{Author details}

${ }^{1}$ Multiple Sclerosis Centre, Department of Public Health, Clinical and Molecular Medicine, University of Cagliari, Cagliari, Italy. '2Department of Biomedical Sciences, Section of Experimental and Clinical Microbiology, University of Sassari, Sassari, Italy. ${ }^{3}$ Department of Public Health, Clinical and Molecular Medicine, University of Cagliari, Cagliari, Italy. ${ }^{4}$ Multiple Sclerosis Centre, Department of medical sciences, University of Cagliari, Cagliari, Italy. 
Received: 14 January 2016 Accepted: 10 August 2016

\section{Published online: 23 August 2016}

\section{References}

1. Cocco E, Murru R, Costa G, Kumar A, Pieroni E, Melis C, et al. Interaction between HLA-DRB1-DQB1 Haplotypes in Sardinian Multiple Sclerosis Population. PLoS One. 2013;8(4):e59790.

2. Kellar-Wood H, Wood NW, Holmans P, Clayton D, Robertson N, Compston DA. Multiple sclerosis and the HLA-D region: linkage and association studies. J Neuroimmunol. 1995;58:183-90.

3. Lampis R, Morelli L, De Virgiliis S, Congia M, Cucca F. The distribution of HLA class II haplotypes reveals that the Sardinian population is genetically differentiated from the other Caucasian populations. Tissue antigens. 2000; 56(6):515-21.

4. Cossu D, Cocco E, Paccagnini D, Masala S, Ahmed N, Frau J, et al. Association of Mycobacterium avium subsp. paratuberculosis with multiple sclerosis in Sardinian patients. PLoS One. 2011;6(4):e18482.

5. Frau J, Cossu D, Coghe G, Lorefice L, Fenu G, Melis M, et al. Mycobacterium avium subsp. paratuberculosis and multiple sclerosis in Sardinian patients: epidemiology and clinical features. Mult Scler. 2013;19(11):1437-42.

6. De Jager PL, Simon KC, Munger KL, Rioux JD, Hafler DA, Ascherio A. Integrating risk factors: HLA-DRB1]1501 and Epstein-Barr virus in multipla sclerosis. Neurology. 2008;70(13 Pt 2):1113-8.

7. Sundqvist E, Sundstrom P, Linden M, Hedstrom AK, Aloisi F, Hillert J, et al. Epstein-Barr virus and multiple sclerosis: interaction with HLA. Genes Immun. 2012;13(1):14-20.

8. Rubicz R, Yolken R, Drigalenko E, Carless MA, Dyer TD, Bauman L, et al. A genome-wide integrative genomic study localizes genetic factors influencing antibodies against Epstein-Barr virus nuclear antigen 1 (EBNA-1). PLoS Genet. 2013;9(1):e1003147.

9. Waubant E, Mowry EM, Krupp L, Chitnis T, Yeh EA, Kuntz N, et al. Antibody response to common viruses and human leukocyte antigen-DRB1 in pediatric multiple sclerosis. Mult Scler. 2013;19(7):891-5.

10. Polman CH, Reingold SC, Banwell B, Clanet M, Cohen JA, Filippi M, et al. Diagnostic criteria for Multiple Sclerosis: 2010 revisions to the McDonald criteria. Ann Neurol. 2011;69:292-302.

11. Kumar A, Sechi LA, Caboni P, Marrosu MG, Atzori L, Pieroni E. Dynamical insights into the differential characteristics of Mycabacterium avium subsp. paratubercolosis peptide binding to HLA-DRB1 proteins associated with multiple sclerosis. New J Chem 2014 doi:10.1039/c4nj01903b.

\section{Submit your next manuscript to BioMed Central and we will help you at every step:}

- We accept pre-submission inquiries

- Our selector tool helps you to find the most relevant journal

- We provide round the clock customer support

- Convenient online submission

- Thorough peer review

- Inclusion in PubMed and all major indexing services

- Maximum visibility for your research

Submit your manuscript at www.biomedcentral.com/submit 